\title{
Using willingness to pay to establish patient preferences for peripheral intravenous catheter securement in an Australian emergency department
}

\author{
Mark Scott*, Simon Bugden, Julia Hocking, Merehau Cindy Mervin, and Claire M Rickard \\ ${ }^{*}$ Corresponding author: Dr Mark Scott, Caboolture Hospital Emergency Department, McKean St, Caboolture, QLD 4510, Australia \\ Email Mark.Scott@health.qld.gov.au
}

Keywords peripheral intravenous catheter, cyanoacrylate, superglue, emergency department, willingness to pay

For referencing Scott $\mathrm{M}$ et al. Using willingness to pay to establish patient preferences for peripheral intravenous catheter securement in an Australian emergency department. Vascular Access 2020; 6(2):6-8.

DOI https://doi.org/10.33235/va.6.2.6-8

\begin{abstract}
Objective To assess patients' willingness to pay (WTP) for adding cyanoacrylate to the peripheral intravenous catheter (PIVC) insertion site to reduce catheter failure at 48 hours.

Background Cyanoacrylate has been associated with a reduction in PIVC failure rate but at a material increased cost of approximately 20\%. Due to the discomfort associated with PIVC replacement, we hypothesised that patients would put value on avoiding such a replacement PIVC and sought to estimate that value.
\end{abstract}

Methods One hundred adult patients presenting to a regional Australian emergency department (ED) and who had a PIVC inserted were surveyed.

Results Thirty three patients would pay AU\$70 to add cyanoacrylate to the standard PIVC, 32 were not willing to pay, and 35 would pay less than $\$ 70$.

Conclusions The average WTP for a novel PIVC securement method was AU\$31.06, which is greater than the cost of using the securement method.

\section{Introduction}

Approximately 14 million intravascular devices are used in Australia each year, the majority of which are peripheral intravenous catheters (PIVCs). ' Despite the high rate of utilisation, the complication rate for PIVCs is high. For example, Wallis and colleagues showed a 36.6\% failure rate in Queensland hospitals, equating to over five million failed PIVCs per year in Australia. ${ }^{2}$ Complications can include dislodgement, phlebitis, occlusion, infiltration, leakage or infection, and any such failure results in interruption to therapy, increased pain and anxiety for the patient, and increased costs to the healthcare system for treatment and insertion of replacement PIVCs. ${ }^{3}$

In general medical/surgical populations, the use of cyanoacrylate at the PIVC insertion site has been found to be associated with lower PIVC failure, although this has not always been statistically significant..$^{3.4}$ In emergency department (ED) patients, an investigation by Bugden and colleagues ${ }^{5}$ found that the addition of two drops of cyanoacrylate (medical grade superglue) in addition to standard intravenous (IV) catheter dressings significantly reduced the PIVC failure rate at 48 hours from 27\% to $17 \%$. The additional material cost of the additional superglue, including removal, was \$13.19. Tuffaha et al. ${ }^{6}$ established the cost of IV catheter replacement at $\$ 61.70$ per IV, but the value that a patient would place on avoiding an IV resite is unknown. We know from prior studies that PIVC insertion is generally unpleasant, 7,8 and we hypothesised that ED patients would put a value on any intervention to reduce the need for PIVC resites. Our aim was to estimate ED patients' willingness to pay (WTP) threshold for the addition of cyanoacrylate at the PIVC insertion site in order to avoid an additional insertion procedure. 


\section{Methods}

\section{Design}

A prospective survey was conducted at the ED of the Caboolture Hospital in Queensland, Australia. The study was approved by the Prince Charles Hospital Human Research Ethics Committee, reference $\mathrm{HREC} / 10 / \mathrm{QPCH} / 137$.

\section{Participants}

A convenience sample of 100 adult patients presenting to the ED who met the primary inclusion criteria of receiving a PIVC as part of their care during the current visit. Patients were identified by a research nurse as eligible for the study and approached for consent while either waiting for results or waiting to be admitted to hospital. This included a brief explanation of the concept of WTP and verbal clarification of patients' understanding of the concept.

\section{Materials}

A detailed information sheet was provided to patients showing photographs of the two different methods of IV securement (simple transparent dressing, with or without glue), potential complications and failure rate that may result in the PIVC needing to be replaced. A patient survey collected demographic data (age, gender, income, employment status, previous IV catheterisation [yes/no]), and a rating of current health state on a scale of 0-100, (0 = "Worst imaginable state of health"; $100=$ "Best imaginable state of health"). The WTP component of the questionnaire asked the following two questions:

Table 1. Distribution of patient characteristics by WTP
1. The current practice for IV dressings at Caboolture Hospital is the standard method. Would you be willing to pay an extra $\$ 70$ for the new method using superglue? YES/NO

2. If you answered NO, what is the maximum extra amount you would be willing to pay for Method 2 (securement using a see-through dressing plus glue)?

\section{Data analysis}

Patients were categorised into those not willing to pay for the addition of cyanoacrylate, those willing to pay less than \$70, and those willing to pay $\$ 70$. Since the justification for cyanoacrylate use is to avoid catheter failure and subsequent replacement, value was based on the cost of PIVC replacement by Tuffaha and colleagues. ${ }^{6}$ Fisher's exact test was used to determine any differences in categorical variables by WTP. Age difference and health rating across groups defining WTP was tested using ANOVA and linear regression using Stata v.15.

\section{Results}

The 100 enrolled patients had an average age of 56 years, were well balanced for gender, and were predominantly not employed (Table 1). Most had previous experience with a PIVC from a previous hospital experience.

A total of 68 of the 100 patients were willing to pay some amount to add superglue, and 32 were unwilling to pay any amount. Of those who would pay, 33 confirmed they would pay $\$ 70$, and 35 indicated they would pay less than $\$ 70$. Of those 35 ,

\begin{tabular}{|c|c|c|c|c|c|c|}
\hline \multirow[t]{2}{*}{ Variable } & \multirow[t]{2}{*}{ Category } & \multicolumn{3}{|c|}{ Willing to pay } & \multirow[t]{2}{*}{ Total } & \multirow[t]{2}{*}{ p-value } \\
\hline & & No & Yes, $<\$ \$ 70$ & Yes, $\$ 70$ & & \\
\hline & & $n=32$ & $n=35$ & $n=33$ & $n=100$ & \\
\hline & & $n(\%)$ & $n(\%)$ & $n(\%)$ & $n(\%)$ & \\
\hline \multirow{2}{*}{ Gender } & Female & $14(43.8)$ & $22(62.9)$ & $16(48.5)$ & $52(52.0)$ & 0.26 \\
\hline & Male & $18(56.3)$ & $13(37.1)$ & $17(51.5)$ & $48(48.0)$ & \\
\hline Health rating & Mean (SD) & $66(21)$ & $51(24)$ & $49(24)$ & $55(24)$ & see Table 2 \\
\hline \multirow{2}{*}{ PIVC previously } & Yes & $29(90.6)$ & $34(97.1)$ & $30(90.9)$ & $93(93.0)$ & 0.56 \\
\hline & No & $3(9.4)$ & $1(2.9)$ & $3(9.1)$ & $7(7.0)$ & \\
\hline \multirow{4}{*}{ Income } & $<=\$ 18,200$ & $17(53.1)$ & $15(42.9)$ & $17(51.5)$ & $49(49.0)$ & 0.51 \\
\hline & $\$ 18,201-37,000$ & $3(9.4)$ & $9(25.7)$ & $6(18.2)$ & $18(18.0)$ & \\
\hline & $\$ 37,001-80,000$ & $8(25.0)$ & $10(28.6)$ & $7(21.2)$ & $25(25.0)$ & \\
\hline & $>\$ 80,000$ & $4(12.5)$ & $1(2.9)$ & $3(9.1)$ & $8(8.0)$ & \\
\hline \multirow{4}{*}{ Employment status } & Not employed & $20(62.5)$ & $24(68.6)$ & $18(54.5)$ & $62(62.0)$ & 0.29 \\
\hline & Casual & $0(0.0)$ & $3(8.6)$ & $1(3.0)$ & $4(4.0)$ & \\
\hline & Part-time & $2(6.3)$ & $1(2.9)$ & $5(15.2)$ & $8(8.0)$ & \\
\hline & Full-time & $10(31.3)$ & $7(20.0)$ & $9(27.3)$ & $26(26.0)$ & \\
\hline Age & Mean (SD) & $60(17.9)$ & $55(20.6)$ & $54(19.0)$ & $56(19.2)$ & 0.45 \\
\hline
\end{tabular}

$\mathrm{SD}=$ Standard deviation; PIVC=peripheral intravenous catheter. 
Table 2. Association between health rating and WTP derived from linear regression model

\begin{tabular}{|l|c|c|c|}
\hline Variable & Coefficient & $\mathbf{9 5 \%}$ Cl & p-value \\
\hline Willingness to pay & & & 0.030 \\
\hline No & Reference category & & \\
\hline Yes, $<\$ 70$ & -15.2 & $-26.5--3.9$ & 0.009 \\
\hline Yes, \$70 & -9.7 & $-21.2-1.7$ & 0.096 \\
\hline Intercept & 63.8 & $55.6-72.0$ & \\
\hline Willingness to pay [yes/no] & & & \\
\hline No & Reference category & & \\
\hline Yes & -12.5 & $-22.5--2.6$ & 0.014 \\
\hline Intercept & 63.8 & $55.6-72.0$ & \\
\hline
\end{tabular}

$\mathrm{Cl}=$ confidence interval

amounts ranged from \$1-60 (median \$20). On average, the 100 patients were prepared to pay $\$ 31.06$

The distribution of patient demographics and previous PIVC experience did not differ significantly by their WTP (Table 1). Regression analysis showed health rating varied significantly by WTP ( $p=0.03$; Table 2). The mean health rating of people willing to pay anything was 12.5 units lower than those not willing to pay.

\section{Discussion and conclusions}

This paper assessed ED patients' WTP for a novel securement method to avoid PIVC failure. Consideration of consumer perspectives is highly important when new technologies such as cyanoacrylate enter the healthcare system. The results indicated that most patients were willing to pay for cyanoacrylate - on average $\$ 31.06$ for this novel securement method, which is $\$ 17.87$ more than its cost. This data supports the introduction of cyanoacrylate into health settings and will be of value to purchasers and policy makers, as well as clinicians seeking institutional support for investment in the product.

Although our data suggests that patients see cyanoacrylate as good value for money, we identified that this was related to their health rating - the lower a patient rated their current state of health, the more willing they were to reduce the pain associated with PIVC failure. Presumably this is because chronic disease and previous negative experiences of PIVC insertion provide motivation to contribute financially to avoid repeated cannulation. Therefore, our results may not be generalisable to patients with better states of health, as well as other patient populations where cyanoacrylate has not been demonstrated to be as effective as in ED patients. Another limitation is that in the Australian health sector, the payer is generally government, with smaller contributions from insurers and patients. Further research is needed to understand patient WTP in other contexts such as in the USA, where payment arrangements differ.

\section{Conflict of interest}

The authors declare no conflicts of interest.

\section{Funding}

The authors received no funding for this study.

\section{References}

1. National Health and Medical Research Council. Australian guidelines for the prevention and control of infection in healthcare. Canberra, Australia: Government of Australia; 2010.

2. Wallis MC, McGrail M, Webster J, Marsh N, Gowardman J, Playford EG, et al. Risk factors for peripheral intravenous catheter failure: a multivariate analysis of data from a RCT. Infect Control Hosp Epidemiol 2014;35:6368.

3. Marsh NM, Webster J, Flynn J, Mihala G, Hewer B, Fraser J, et al. Securement methods for peripheral venous catheters: a pilot RCT. J Vasc Access 2015;16:237-44.

4. Rickard CM, Marsh N, Webster J, Runnegar N, Larsen E, McGrail MR, et al. Dressings and securements for the prevention of peripheral intravenous catheter failure in adults (SAVE): a pragmatic, randomised controlled, superiority trial. Lancet 2018;392(10145):419-3.

5. Bugden S, Shean K, Scott M, Mihala G, Clark S, Johnstone C, et al. Skin glue reduces the failure rate of emergency department-inserted PIVCs: an randomized controlled trial. Annals Emerg Med 2016;68:196-201.

6. Tuffaha HW, Rickard CM, Webster J, Marsh N, Gordon L, Wallis M, et al. Cost-effectiveness analysis of clinically indicated vs routine replacement of peripheral intravenous catheters. Appl Health Econ Health Pol 2014;12:51-58

7. Robinson-Reilly M, Paliadelis P, Cruickshank M. Venous access: the patient experience. Support Care Cancer 2016;24(3):1181-7.

8. Cooke M, Ullman AJ, Ray-Barruel G, Wallis M, Corley A, Rickard CM. Not "just" an intravenous line: consumer perspectives on peripheral intravenous cannulation (PIVC). An international cross-sectional survey of 25 countries. PLoS One 2018;13(2):e0193436). 